\title{
Maintenance of villus height and crypt depth, and enhancement of disaccharide digestion and monosaccharide absorption, in piglets fed on cows' whole milk after weaning
}

\author{
BY JOHN R. PLUSKE ${ }^{1 *}$, MELINDA J. THOMPSON ${ }^{2}$, CRAIG S. ATWOOD ${ }^{2 \dagger}$, \\ PETER H. BIRD ${ }^{2} \ddagger$ IAN H. WILLIAMS ${ }^{1}$ AND PETER E. HARTMANN ${ }^{2}$ \\ ${ }^{1}$ Animal Science, Faculty of Agriculture, University of Western Australia, Nedlands, WA 6907 , \\ Australia \\ ${ }^{2}$ Department of Biochemistry, University of Western Australia, Nedlands, WA 6907, Australia
}

(Received 3 April 1995 - Revised 2 January 1996-Accepted 10 January 1996)

\begin{abstract}
The aims of the present study were (a) to maintain the structure and function of the small intestine of the piglet after weaning, and (b) to compare the capacity in vivo of sucking and weaned piglets to digest oral boluses of lactose and sucrose and absorb their monosaccharide products. Piglets were fed on cows' whole milk ad libitum every $\mathbf{2}$ h for $5 \mathrm{~d}$ after weaning. Physiological doses of lactose plus fructose (treatment LAC + FRU) and sucrose plus galactose (treatment SUC + GAL) were administered on day 27 of lactation and on the fifth day after weaning, after which time piglets were killed. Villus height and crypt depth were maintained $(P>0.05)$ by feeding cows' milk after weaning. The areas under the curves (AUC) for galactose and glucose, adjusted for live weight and plasma volume, increased $(P<0.05)$ after weaning. Despite the enhancement of gut function after weaning, the galactose index (Gall: AUC for galactose ingested as lactose divided by the AUC for the same dose of galactose ingested as the monosaccharide) and fructose index (FruI: AUC for fructose ingested as sucrose divided by the AUC for the same dose of fructose ingested as the monosaccharide), which are indices of digestive and absorptive efficiency, both decreased after weaning. This apparent anomaly may be reconciled by increased growth, and hence surface area, of the small intestine between weaning and slaughter such that 'total' digestion and absorption most probably increased despite apparent decreases in GalI and FruI. Positive correlations $(P<0.05)$ between villus height and Gall are consistent with the maximum activity of lactase occurring more apically along the villus. Significant linear relationships $(P<0$-05) were recorded between villus height at the proximal jejunum and adjusted AUC for galactose and glucose following treatment LAC + FRU, and between villus height at the proximal jejunum and adjusted glucose AUC following treatment SUC + GAL. These relationships suggest that maximum digestion and absorption occurs at increasing distances along the crypt:villus axis in the weaned pig.
\end{abstract}

Piglet: Sugars: Villus height: Crypt depth

Lactase (EC 3.2.1.23) activity in the small-intestinal mucosa of the newborn pig is high at birth and declines gradually during the first 2 months of life (Manners \& Stevens, 1972; James et al. 1987). By comparison, the activity of sucrase (EC 3.2.1.48) is generally absent, or present at very low levels, at birth but increases with age (Kidder \& Manners, 1980). Gay et al. (1976) reported an apparent 'loss' of lactase and sucrase activity attributable to weaning, an effect that has both been confirmed (Hampson \& Kidder, 1986; Miller et al. 1986) and refuted (Kelly et al. $1991 b, c$; Pluske et al. 1996a,b) since. Nevertheless, weaning is coincidental with a reduction in villus height and an increase in crypt depth (Hornich et

* Present address: Monogastric Research Centre, Massey University, Palmerston North, New Zealand.

$\uparrow$ Present address: National Cancer Institute, National Institute of Health, Bethesda, MD, USA.

$\ddagger$ Present address: CSIRO Division of Wildlife and Ecology, PO Box 84, Lyneham, ACT 2602, Australia. 
al. 1973; Gay et al. 1976; Kenworthy, 1976; Hampson, 1986a, b; Miller et al. 1986; Cera et al. 1988; Kelly et al. 1990, 1991 b, c; Nabuurs et al. 1993; Pluske et al. 1996a, b) that leaves fewer and less-differentiated enterocytes on villi available for the digestion of nutrients (Smith, 1984; Hampson, 1986a; Hampson \& Kidder, 1986). A concomitant reduction in the capacity of the small intestine to absorb xylose (Miller et al. 1984; Hampson \& Kidder, 1986; Hampson \& Smith, 1986), alanine (Smith, 1984; Miller et al. 1986), and electrolytes (Nabuurs et al. 1994), has also been reported after weaning.

Our previous studies demonstrated that villus height and crypt depth could be maintained in piglets after weaning by feeding a milk diet at intervals of $2 \mathrm{~h}$ (Pluske $e t$ al. $1996 a, b)$. Under this regimen piglets fed ad libitum grew at rates of empty-body-weight gain (i.e. $407-463 \mathrm{~g} / \mathrm{d}$ ) indicative of a gut that was not impaired in its digestive and absorptive function. However, digestive enzyme activity and assessment of absorptive capacity using xylose failed to ratify both the maintenance of villus height and the exemplary rate of growth displayed by piglets after weaning. Similarly, Kelly et al. (1991 b, c) reported ambiguity between the histological structure and digestive and absorptive function of the small intestine using in vitro techniques, and concluded that digestive enzyme activities in vitro, regardless of their basis of expression, can only provide a crude assessment of digestive capacity in vivo. There is a need, therefore, to establish techniques that provide an assessment in vivo of the digestive and absorptive capacity of the young pig.

The recent development of sensitive biochemical assays has allowed disaccharide hydrolysis and monosaccharide metabolism to be studied in vivo in the small intestine of human infants (Kliegman \& Sparks, 1985; Siegel et al. 1988), adults (Williams et al. 1983), lambs (Kaempf et al. 1988, 1990; Spedale et al. 1992) and foals (Rice et al. 1992) under natural nursing conditions. In sucking piglets, Holmes et al. (1990) investigated the metabolism of lactose and galactose following ingestion of milk during letdown, and Bird \& Hartmann $(1994,1996)$ and Bird et al. (1995) extended these studies to gain a further understanding of the digestion of lactose and sucrose and the metabolism of galactose, glucose and fructose in sucking piglets. However, these in vivo methods of investigation have not been conducted in weaner pigs.

The purpose of the present study was (a) to maintain villus height and crypt depth after weaning and, having done this, (b) to compare the capacity in vivo of brush-border lactase and sucrase to digest oral boluses of lactose and sucrose, and of the small intestine to absorb their monosaccharides, in sucking and weaned piglets. Since piglets were maintained on cows' milk after weaning, we hypothesized that the capacity in vivo of lactase and sucrase to digest lactose and sucrose would be maintained after weaning. In addition, brush-border lactase activity in the young pig has a more apical distribution on the villus than does sucrase (Dahlqvist \& Nordström, 1966; Nordström \& Dahlqvist, 1973; Kelly et al. 1991 a) and may therefore be expected to show a greater reduction in activity after weaning in response to a change in villus height. For this part of the study we hypothesized that lactase activity in vivo, but not that of sucrase, is correlated to villus height after weaning.

\section{MATERIALS AND METHODS}

Animals and housing

Healthy 27 -d-old sucking piglets $(n 6)$ and 33 -d-old piglets $(n 12)$ that were weaned at 28 (SE 0.4) d and weighed 7.9 (SE 0.34) kg were selected for the study. At weaning piglets were transported to an experimental room that contained twelve individual stainless-steel pens arranged in four banks of three pens each. Each pen had a measured floor area of $0.45 \mathrm{~m}^{2}$. Ambient temperature was maintained at 25.6 (SE 0.44) $)^{\circ}$ Two galvanized troughs were placed in each pen, one for feed and the other for fresh water. 


\section{Feeding}

After weaning piglets were offered cows' whole milk ad libitum every $2 \mathrm{~h}$. The amount of milk fed was increased by $10 \%$ at each feed if the piglet consumed all the milk offered to it in the previous meal, ensuring that more milk was offered than could be drunk. Piglets were given $30-45$ min to drink the milk placed in front of them, after which time troughs were removed from each pen and any residual milk was noted. Between feedings all troughs were washed and scrubbed thoroughly with hot water.

\section{Oral doses and blood sampling}

Two solutions were prepared. The first contained lactose and fructose (treatment LAC + FRU) and the second contained sucrose and galactose (treatment SUC+GAL). Both solutions were prepared using doubly-deionized water $12-24 \mathrm{~h}$ before they were administered. They were kept in glass bottles with an airtight seal at $4^{\circ}$ before use. Before oral dosing, the solutions were equilibrated to room temperature $\left(20-25^{\circ}\right)$.

At 09.00 hours on day 27 of lactation six sucking piglets were selected and moved to a pen in a neighbouring room. Piglets were watched beforehand to ensure they had not drunk from the sow in the previous hour. Similarly, at 09.00 hours on the fifth day after weaning, six piglets were selected and moved to a pen in an adjacent room. These were fed in a manner that ensured they had not consumed any milk in the previous hour. All piglets were dosed orally (via stomach tube) with $25 \mathrm{ml}$ of each solution containing either $4 \mathrm{~g}$ lactose plus $2 \mathrm{~g}$ fructose or $4 \mathrm{~g}$ sucrose plus $2 \mathrm{~g}$ galactose in succession. Both doses were of the same osmolality, and therefore would have led to similar rates of stomach emptying.

Administration time for each dose was between 0.5 and 2 min with zero time being taken as the time when half the volume of the solution had been administered. Ear veins of the piglets were pricked using a finger lancet, and blood samples (about $60 \mu 1$ ) were collected into heparinized capillary tubes and immediately placed on ice. Following blood collection each capillary tube was sealed at one end with a disposable micro-packed cell volume tube closure, and the plasma was separated by centrifugation, isolated, and stored at $-20^{\circ}$ for subsequent analysis. Samples were taken at regular intervals (3-5 min) for $60 \mathrm{~min}$ and then again at 75 and $90 \mathrm{~min}$ after dosing. After samples from this first dose were completed, the other solution was administered and blood samples were collected again for $90 \mathrm{~min}$.

\section{Post-mortem procedure}

On the day of weaning ( $n 4)$, and on the fifth day after weaning ( $n 12)$, piglets were killed and samples of small intestine at sites 25,50 and $75 \%$ along the gut were taken for subsequent histological examination. The slaughter, post-mortem procedure and preparation of gut samples for measurement of villus height and crypt depth have been described previously (Pluske et al. 1996a).

\section{Biochemical analysis}

Plasma (20 $\mu \mathrm{l}$ ) was deproteinized using $200 \mu 1$ 0-6 M-perchloric acid (Arthur et al. 1989). The concentration of glucose was measured by the glucose oxidase (EC 1.1.3.4) method of Bergmeyer \& Bern't (1974) as modified by Holmes et al. (1990). Galactose concentration was determined by the bioluminescence method of Arthur et al. (1989), with adaptations, and fructose concentration was determined according to the method of Guppy et al. (1990).

\section{Data analysis}

The concentrations of glucose, galactose and fructose in the blood $v$. time after oral dosing were plotted and the area under the curve (AUC) for each piglet was calculated by the 
trapezoid method reported by Williams et al. (1983), which was derived from Yeh \& Kwan (1978). Since piglets of different live weights were administered the same amount of LAC + FRU and SUC+GAL, heavier piglets would have distributed the absorbed monosaccharides in a larger volume of plasma. It was necessary, therefore, to adjust the AUC to account for the different dilution of the monosaccharides in piglets differing in live weight. Bird \& Hartmann (1994) provide a full description of the methods and calculations used to allow comparisons of AUC between piglets of different live weights.

Galactose and fructose indexes both before and after weaning were calculated from the adjusted AUC. By dividing the adjusted AUC values for galactose and fructose (ingested as components of lactose and sucrose, respectively) by the values obtained for galactose and fructose ingested as monosaccharides respectively, and then expressing the ratio as a percentage, an index equivalent to the glycaemic index used in human nutrition (Brand Miller et al. 1994) was obtained. The galactose index (GalI) and the fructose index (FruI), therefore, provide an index of efficiency in vivo of disaccharide digestion and monosaccharide absorption in the small intestine. Thus if, for example, the Gall was $50 \%$, then the AUC for galactose consumed as lactose was half that observed when the same quantity of galactose was ingested as the monosaccharide.

\section{Statistical analysis and presentation of results}

Performance data after weaning are presented as mean, SEM, CV and the range of values encountered. Weight of the empty body was determined by multiplying the starting live weight of each piglet by the percentage of the carcass that was empty body in the piglets killed at weaning (Noblet \& Etienne, 1987). This percentage was 98.2 (SE 0.26) \% (CV 0.27\%). Empty-body-weight gain was calculated, therefore, as the difference between the recorded weight of the empty body at slaughter $5 \mathrm{~d}$ after weaning and the estimated weight of the empty body at weaning.

Significant differences in adjusted AUC for glucose, galactose and fructose between sucking and weaned piglets were determined using unpaired Student's $t$ test. Results are expressed as means with their standard errors. Simple linear regressions were performed to describe relationships between gut structure and adjusted AUC for products of lactose and sucrose hydrolysis. One-way ANOVA was used to study differences in structure of the small intestine between piglets killed before and after weaning.

\section{RESULTS}

Villus height and crypt depth after weaning

Feeding cows' whole milk to piglets for $5 \mathrm{~d}$ after weaning maintained $(P>0.05)$ villus height at each site along the small intestine compared with piglets killed at weaning. Villus height in weaned piglets ranged from $570 \mu \mathrm{m}$ at the proximal jejunum to $342 \mu \mathrm{m}$ at the distal ileum (Table 1). Crypt depth was similar $(P>0.05)$ between weaned and unweaned pigs at sites 25 and $50 \%$ along the gut, but at the distal ileum, crypts were $24 \%$ deeper (137v. $110 \mu \mathrm{m}, P<0.05)$ in piglets fed on cows' milk than in piglets killed at weaning. The villus height: crypt depth ratio was similar $(P>0.05)$ for both groups of animals (Table 1$)$.

\section{Adjusted areas under the curves}

The adjusted AUC for galactose, glucose and fructose following treatment LAC + FRU were highest in piglets assessed $5 \mathrm{~d}$ after weaning. For example, the adjusted AUC for galactose was $65 \%$ higher in weaned piglets $(5600 v .3399, P=0.016)$ than that recorded in piglets before weaning. When piglets were dosed with treatment SUC + GAL the adjusted AUC for galactose and glucose were $107 \%(P=0.007)$ and $31 \%(P<0.001)$ 
Table 1. Villus height $(\mu \mathrm{m})$, crypt depth $(\mu \mathrm{m})$ and villus height:crypt depth ratio $(V H: C D)$ of piglets killed either at weaning (n 4) or $5 d$ later (n 12) $\dagger$

\begin{tabular}{|c|c|c|c|c|c|c|}
\hline \multirow[b]{2}{*}{ Variable } & \multirow{2}{*}{$\begin{array}{c}\% \text { of } \\
\text { intestine }\end{array}$} & \multicolumn{2}{|c|}{ Weaning } & \multicolumn{2}{|c|}{ After weaning } & \multirow{2}{*}{$\begin{array}{c}\text { Statistics } \\
\text { (15 edf) }\end{array}$} \\
\hline & & Mean & $\mathbf{S E}$ & Mean & $\mathbf{S E}$ & \\
\hline Villus height & $\begin{array}{l}25 \\
50 \\
75\end{array}$ & $\begin{array}{l}550 \\
523 \\
427 \\
500\end{array}$ & $\begin{array}{l}66 \cdot 1 \\
82 \cdot 2 \\
45 \cdot 1 \\
54 \cdot 0\end{array}$ & $\begin{array}{l}570 \\
513 \\
342 \\
476\end{array}$ & $\begin{array}{r}24 \cdot 4 \\
27 \cdot 1 \\
29 \cdot 4 \\
8 \cdot 5\end{array}$ & $\begin{array}{l}\text { NS } \\
\text { NS } \\
\text { NS } \\
\text { NS }\end{array}$ \\
\hline Crypt depth & $\begin{array}{l}25 \\
50 \\
75\end{array}$ & $\begin{array}{l}130 \\
140 \\
110^{\mathrm{a}} \\
127\end{array}$ & $\begin{array}{r}7.6 \\
14.5 \\
9 \cdot 7 \\
22.2\end{array}$ & $\begin{array}{l}126 \\
128 \\
137^{\mathrm{b}} \\
130\end{array}$ & $\begin{array}{r}4 \cdot 4 \\
3 \cdot 2 \\
9 \cdot 5 \\
12 \cdot 8\end{array}$ & $\begin{array}{c}\text { NS } \\
\text { NS } \\
* \\
\text { NS }\end{array}$ \\
\hline Mean $\neq \mathrm{VH}: \mathrm{CD}$ ratio & & $4 \cdot 0$ & 0.60 & $3 \cdot 7$ & $0 \cdot 25$ & NS \\
\hline
\end{tabular}

a,b Mean values within a row with unlike superscript letters were significantly different, $P<0 \cdot 05$.

* $P<0.05$.

$\dagger$ For details of procedures, see pp. 410-411.

$\ddagger$ Mean of all three sites along the small intestine.

Table 2. Adjusted area under the curve values (arbitrary units) for galactose, glucose and fructose for pigs dosed before weaning and on the fifth day after weaning with lactose plus fructose (treatment $L A C+F R U$ ) and sucrose plus galactose (treatment $S U C+G A L) \dagger$

(Mean values with their standard errors for six piglets)

\begin{tabular}{|c|c|c|c|c|c|}
\hline & \multicolumn{2}{|c|}{$\begin{array}{l}\text { Before weaning } \\
\text { (day 27) }\end{array}$} & \multicolumn{2}{|c|}{$\begin{array}{l}\text { After weaning } \\
\text { (day 33) }\end{array}$} & \multirow{2}{*}{$\begin{array}{l}\text { Statistics } \\
\text { (11 edf) }\end{array}$} \\
\hline & Mean & SEM & Mean & SEM & \\
\hline \multicolumn{6}{|c|}{ Treatment $\mathrm{LAC}+\mathrm{FRU}$} \\
\hline Galactose & $3399^{\mathrm{a}}$ & $426 \cdot 8$ & $5600^{\mathrm{b}}$ & 625.9 & $*$ \\
\hline Glucose & $239^{4}$ & $11 \cdot 3$ & $465^{b}$ & 15.0 & $* * *$ \\
\hline Fructose & $18021^{\mathrm{a}}$ & $1564 \cdot 5$ & $39462^{b}$ & $4594 \cdot 1$ & $* * *$ \\
\hline \multicolumn{6}{|c|}{ Treatment SUC+GAL } \\
\hline Galactose & $4792^{\mathrm{a}}$ & 902.5 & $12017^{b}$ & $1627 \cdot 0$ & ** \\
\hline Glucose & $309^{a}$ & $11 \cdot 3$ & $404^{b}$ & $18 \cdot 3$ & $* * *$ \\
\hline Fructose & 15199 & $1559 \cdot 2$ & 17809 & 4833.7 & NS \\
\hline
\end{tabular}

a,b Mean values within a row with unlike superscript letters were significantly different.

* $P<0.05, * * P<0.01,{ }^{* * *} P<0.001$.

$\dagger$ For details of procedures, see pp. $410-412$.

higher respectively, for piglets assessed $5 \mathrm{~d}$ after weaning compared with those assessed on day 27 of lactation. There was no difference $(P=0.618)$ in the adjusted AUC for fructose before and after weaning following treatment SUC+GAL (Table 2).

Galactose index and fructose index

The Gall on the day before weaning was $58.7 \%$ and had declined to $46.6 \%$ by the fifth day after weaning, whereas the FruI on day 27 was $84.3 \%$ but had declined to $45.1 \%$ when assessed after weaning. 
Villus height at a site $25 \%$ along the gut explained $87 \%(P=0.007)$ of the variation in GalI (Fig. 1(a)), and mean villus height along the entire length of the gut accounted for $70 \%(P=0.037)$ of the GalI (Fig. 1(b)). In contrast, no significant relationships $\left(R^{2} 0.01-0.15, P>0.05\right)$ were found between villus height at any site along the gut, and mean villus height, and FruI after weaning.

\section{Relationships between villus height and adjusted areas under the curves}

Correlations between villus height at the proximal jejunum and the adjusted AUC for galactose, glucose and fructose following treatments LAC +FRU (graphs a-c) and SUC + GAL (graphs $d-f$ ) are depicted in Fig. 2. Villus height at the proximal jejunum explained $70 \%(P=0.039)$ and $81 \%(P=0.015)$ of the adjusted AUC for galactose (Fig. 2(a)) and glucose (Fig. 2(b)) respectively, following treatment LAC + FRU on the fifth day after weaning. The adjusted AUC for fructose was not related $\left(R^{2} 0 \cdot 19, P>0.05\right)$ to villus height following treatment LAC + FRU (Fig. 2(c)).

Following treatment SUC + GAL, only the adjusted AUC for glucose was correlated with villus height at a site $25 \%$ along the gut $\left(R^{2} 0 \cdot 74, P=0.027\right.$; Fig. $\left.2(\mathrm{e})\right)$. The adjusted AUC for galactose and fructose (Fig. 2(d) and (f)) were not related ( $R^{2} 0.02$ and 0.22 for galactose and fructose respectively; $P>0.05$ ) to villus height after weaning. No significant correlations were found for sites 50 and $75 \%$ along the small intestine, nor for mean villus height, for the adjusted AUC of any monosaccharides following treatments LAC + FRU or SUC+GAL.

Significant negative relationships were found for correlations between crypt depth at sites 25 and $50 \%$ along the small intestine and the adjusted AUC for glucose following treatment LAC + FRU. Crypt depth $(x)$ at the proximal jejunum explained $85 \%$ of the variation in the adjusted glucose AUC $(y)$ :

$$
y=769 \cdot 2-2 \cdot 29 x, \mathrm{~F}_{1,4} 22 \cdot 10, P=0 \cdot 009 ; R^{2} 0 \cdot 85,
$$

while crypt depth $(x)$ at the mid jejunum explained $82 \%$ of the total variation in the adjusted glucose AUC $(y)$ :

$$
y=836 \cdot 9-2 \cdot 82 x, \mathrm{~F}_{1,4} 18 \cdot 79, P=0 \cdot 012 ; R^{2} 0 \cdot 82 .
$$

Following treatment SUC + GAL, significant negative relationships were found also between crypt depth at the proximal and mid jejunum, and with mean crypt depth along the entire length of the small intestine, as follows:

(a) crypt depth at $25 \%(x)$ and adjusted glucose AUC $(y)$ :

$$
y=783 \cdot 8-2 \cdot 86 x, \mathrm{~F}_{1,4} 30.06, P=0.005 ; R^{2} 0 \cdot 88 ;
$$

(b) crypt depth at $50 \%(x)$ and adjusted glucose AUC $(y)$ :

$$
y=859 \cdot 2-3 \cdot 46 x, \mathrm{~F}_{1,4} 20 \cdot 95, P=0 \cdot 012 ; R^{2} 0 \cdot 83 ;
$$

(c) mean crypt depth $(x)$ and adjusted glucose AUC $(y)$ :

$$
y=668.4-1.91 x, \mathrm{~F}_{1,4} 11 \cdot 66, P=0.027 ; R^{2} 0 \cdot 74 \text {. }
$$

Piglet performance after weaning

The general health of all piglets during the experiment was excellent. Animals averaged an empty-body-weight of $268 \mathrm{~g} / \mathrm{d}$ (live-weight gain $315 \mathrm{~g} / \mathrm{d}$ ) from weaning and consumed, on average, $238 \mathrm{~g}$ milk DM/d, or 5.5 MJ gross energy/d, over the duration of the study. Piglets converted milk DM to empty-body-weight gain at an efficiency of 0.8 and used, on average, $23 \mathrm{~kJ}$ digestible energy to deposit $1 \mathrm{~g}$ empty-body-weight gain (Table 3). 

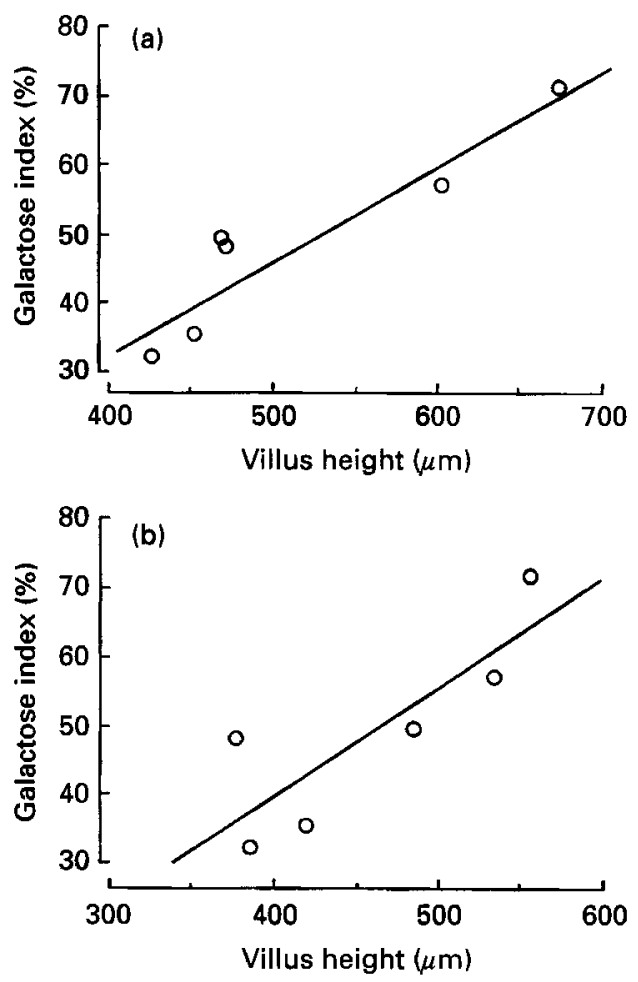

Fig. 1. Relationships between (a) villus height at a site $25 \%$ along the small intestine $(y=-20 \cdot 8+0 \cdot 14 x$, $\left.P=0.007, R^{2} 0.87\right)$ and (b) mean villus height along the entire length of the small intestine $(y=-23.3+0.16 x$, $P=0.037, R^{2} 0.70$ ), and the galactose index assessed $5 \mathrm{~d}$ after weaning. Each point represents an individual pig.

\section{DISCUSSION}

Villus height and crypt depth

Feeding cows' whole milk at intervals of $2 \mathrm{~h}$ for $5 \mathrm{~d}$ after weaning maintained villus height compared with piglets killed at the time of weaning. This concurs with results found in earlier experiments (Pluske et al. 1996a,b) and provides further evidence that gut structure can be maintained if piglets are coaxed to drink milk immediately after weaning to avoid the period of temporary 'starvation' that commonly occurs. Since villus height is correlated with the number of enterocytes on the villus column in 'normal' villi (Wright, 1982; Hampson, 1986a), the attenuation of voluntary feed intake after weaning must have preserved enterocyte number commensurate with a maintenance, or even enhancement (e.g. James et al. 1988), of digestive and absorptive capacity of each enterocyte. The lack of any increase in crypt-cell production rate after weaning supports this notion. An alternative reason for preservation of villus height, as suggested by Goodlad et al. (1988), is that villus cell population might increase by means of cell migration from the crypts without a concomitant increase in crypt-cell production rate. However, this has only been observed in rats re-fed after a period of short-term starvation (Altmann, 1972; Clarke, 1975), and so this mechanism is unlikely to be responsible for the maintenance of villus height seen after weaning in the present investigation. 


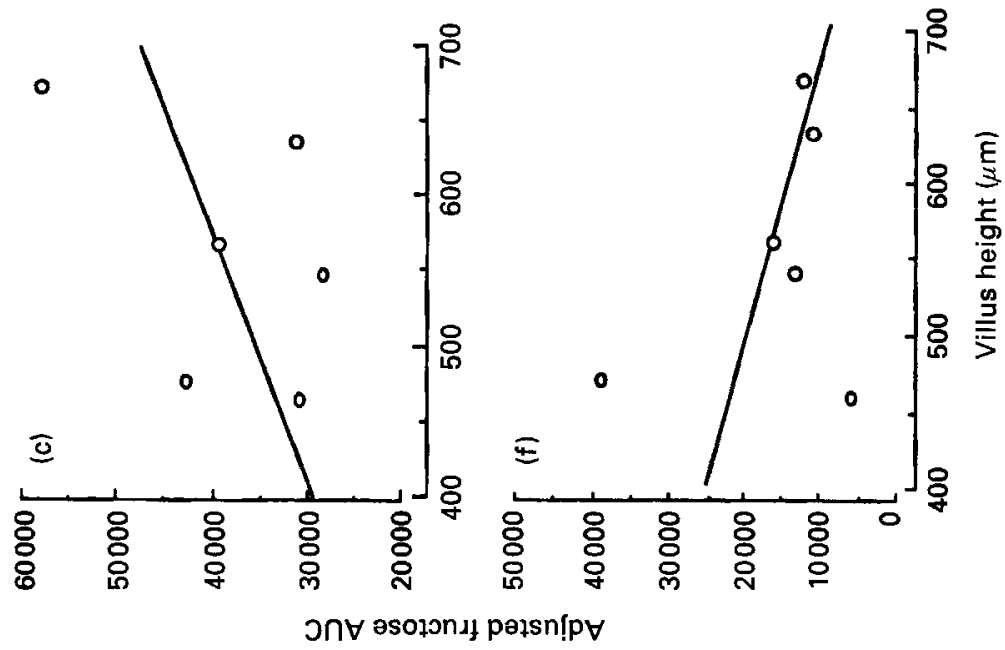

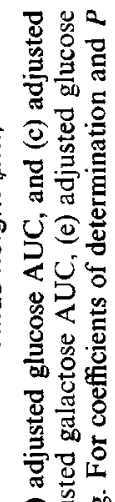

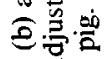

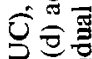
过 政
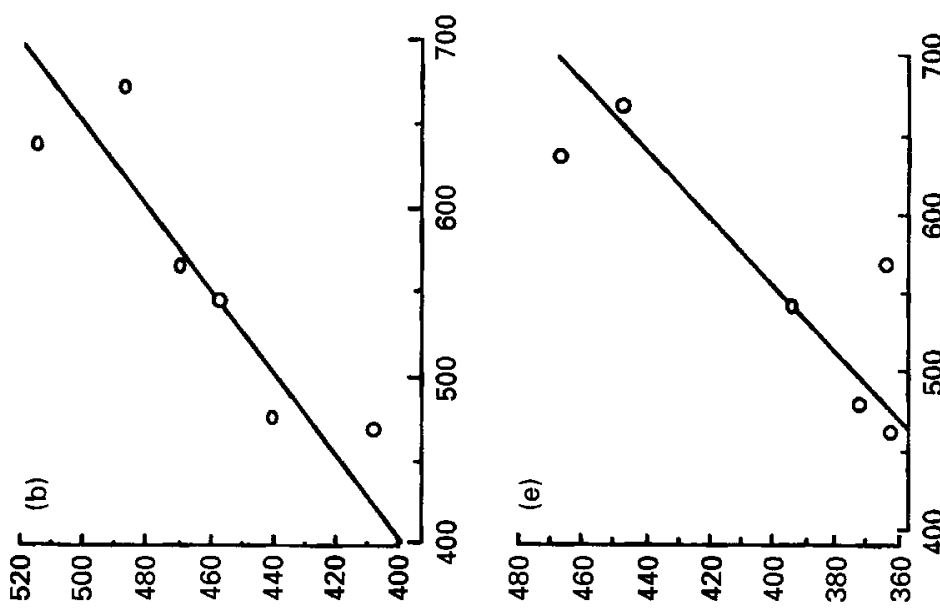

응 $\overline{\mathrm{E}}$

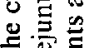
총

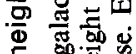

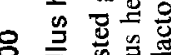

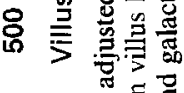

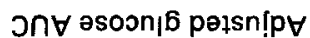
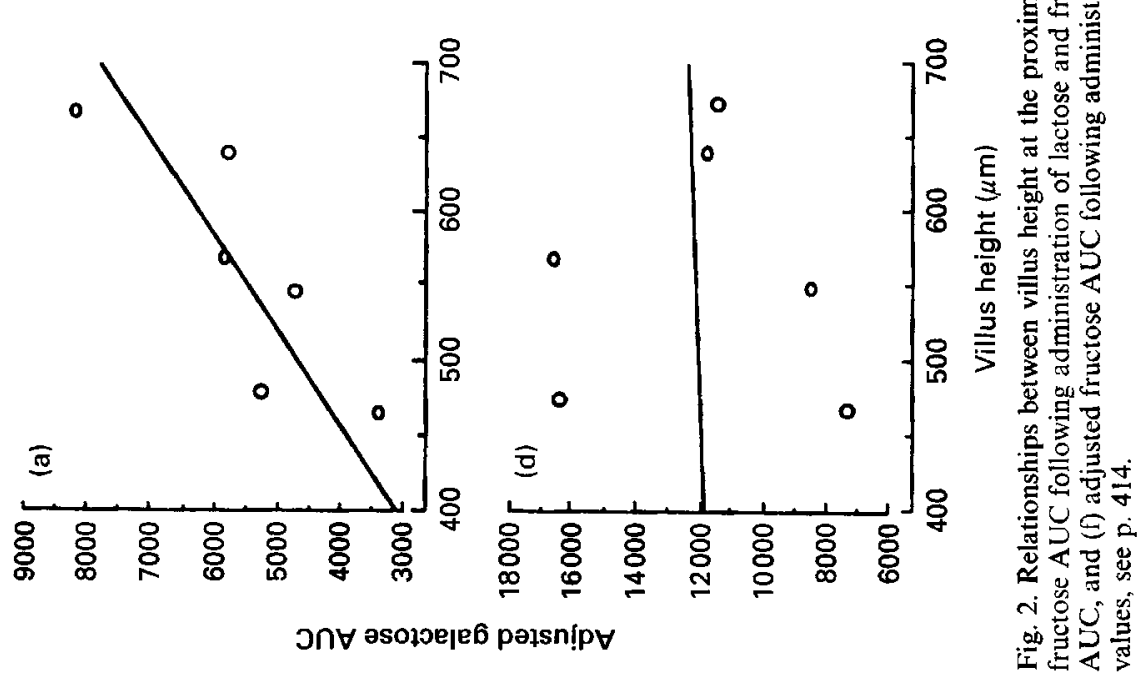

政

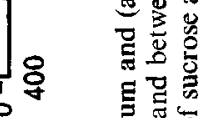
镸宛 记 埕㝴 훙 政 등ㅎㅇ 든 要罚 
Table 3. Empty body weight (EBW), voluntary feed intake (VFI), feed conversion ratio $(F C R)$, and the energy cost of body deposition of pigs fed on cows' whole milk ad libitum for 5 days after weaning (n 12)

\begin{tabular}{|c|c|c|c|c|}
\hline & Mean & SEM & $\begin{array}{l}\text { CV } \\
(\%)\end{array}$ & Range \\
\hline EBW at weaning $(\mathrm{kg})$ & $7 \cdot 7$ & 0.22 & $9 \cdot 7$ & $6.4-8.7$ \\
\hline EBW after $5 \mathrm{~d}(\mathrm{~kg})$ & $9 \cdot 1$ & 0.30 & $11 \cdot 5$ & $7 \cdot 4-10 \cdot 7$ \\
\hline Live-weight gain $(\mathrm{g} / \mathrm{d})$ & 315 & $33 \cdot 4$ & $36 \cdot 7$ & $114-456$ \\
\hline EBW gain $(\mathrm{g} / \mathrm{d})$ & 268 & 31.9 & $41 \cdot 2$ & $59-406$ \\
\hline VFI $(\mathrm{g} \mathrm{DM} / \mathrm{d})$ & 238 & 17.7 & $25 \cdot 7$ & $130-333$ \\
\hline Energy intake (MJ GE/d) & $5 \cdot 5$ & 0.41 & $25 \cdot 7$ & $3 \cdot 8-7 \cdot 6$ \\
\hline FCR (g DM:g EBW gain) & 0.8 & 0.06 & $27 \cdot 1$ & $0 \cdot 5-1 \cdot 1$ \\
\hline Energy cost/g EBW gain (kJ DE/g) & $23 \cdot 0$ & $2 \cdot 85$ & $42 \cdot 8$ & $14 \cdot 5-48 \cdot 8$ \\
\hline
\end{tabular}

GE, gross energy; DE, digestible energy.

\section{Adjusted areas under the curves, and the galactose and fructose indexes}

The Gall and FruI provide a qualitative index of the capacity of lactase and sucrase in vivo to hydrolyse lactose and sucrose, and the capacity in vivo of enterocytes to absorb their monosaccharide products. There was an increase in Gall after weaning, indicating that more of the monosaccharide appeared in the peripheral circulation (Table 2). Since the values were corrected for differences in live weight, the increased Gall could have been caused by an enhancement in the digestive and/or absorptive capacity of the small intestine. Despite increases in the amount of monosaccharide entering the peripheral circulation, there were apparent decreases in GalI (from 58.7 to $46.6 \%$ ) and FruI (from 84.3 to $45.1 \%$ ) between weaning and slaughter $5 \mathrm{~d}$ later suggesting a decrease in the efficiencies of lactase and sucrase respectively. One explanation for this apparent anomaly between adjusted AUC and both Gall and FruI is the increased growth (and hence surface area) of the small intestine that occurred between weaning and slaughter such that 'total' digestion and absorption most probably increased despite apparent decreases in the activity of lactase and sucrase in vivo. In the present study the absolute $(\mathrm{g})$ and relative $(\mathrm{g} / \mathrm{kg}$ empty-body weight) weights of the small intestine increased from 171 to 285 , and from 24.6 to 31.5 respectively, in the $5 \mathrm{~d}$ after weaning. Similarly, small-intestine length increased from $6 \cdot 31$ to $8.05 \mathrm{~m}$.

The Gall on day 27 of lactation was $58.7 \%$, and is in good agreement with the value of $66 \%$ for 'relative digestive capacity' of lactase reported by Bird et al. (1995) in piglets from 2 to $18 \mathrm{~d}$ of age. The decline in Gall after weaning is consistent with the observations of Walker (1959) and Ekstrom et al. (1975) who showed that, based on the calculation of total intestinal lactase, the capacity of brush-border lactase to hydrolyse lactose was maximum between 15 and $21 \mathrm{~d}$ of age and declined thereafter. Similarly, Kelly et al. (1991 $a$ ) reported that biochemically active lactase declined significantly in the brush border of piglets in their first 8 weeks of life. Thus, lactase activity measurements reported by other workers are consistent with the changes observed for Gall.

Also in agreement with the data of Kelly et al. (1991 a) was our finding that maximum lactase activity occurred further along (i.e. more apically) the crypt:villus axis (Fig. 1). Kelly et al. (1991 a) reported that in normally suckled piglets, lactase activity at 5 weeks of age continued to increase during enterocyte migration up the villus, although in piglets killed at 7 and 8 weeks of age maximal activity of lactase was expressed at decreasing distances from the villus: crypt junction. These authors concluded that lactation products 
(i.e. substances in milk such as hormones and growth factors) can accelerate the rate of decline of brush-border lactase. It is likely that similar compounds were present in the cows' milk we fed in this experiment and hence may also have contributed to the apparent decline in GalI. It would appear, therefore, that in the young piglet the functional limitation to its capacity to utilize lactose as an energy source is the hydrolytic activity of brush-border lactase. Bird et al. (1995) consistently recorded a lower adjusted galactose AUC following a dose of lactose compared with an iso-osmotic dose of glucose plus galactose in sucking piglets. Evidence of this occurred in the present experiment because the adjusted galactose AUC was higher when administered as a monosaccharide (treatment SUC + GAL) than when given as the disaccharide in treatment LAC + FRU (Table 2).

The aetiology of lactase decline is not clear but may be related to a reduction in enterocyte lifespan (Tsuboi et al. 1981, 1985), a suppression in the rate of enzyme synthesis (Jonas et al. 1985; Kelly et al. 1991a), and/or a two-stage decline in the regulation of lactase expression involving both a shortening of the time allowed for enzyme expression on the villus and an inhibition in the rate at which lactase is expressed (Smith \& James, 1987).

We calculated that the FruI in piglets aged $27 \mathrm{~d}$ of age was $84.3 \%$ and that this declined to $45.1 \%$ by the fifth day after weaning. Bird \& Hartmann (1996) examined the relative digestive capacity for sucrase activity in piglets from 2 to $15 \mathrm{~d}$ of age and recorded a positive linear correlation between piglet age and the capacity to hydrolyse sucrose $\left(R^{2} 0.96\right.$, $P<0.001)$. The oldest piglets examined $(15 \mathrm{~d})$ had a digestive capacity of $97 \%$, considerably higher than the $84 \%$ recorded in the present experiment for pigs $27 \mathrm{~d}$ of age. What is unclear is whether the relationship described by Bird \& Hartmann (1996) can be applied to piglets older than $15 \mathrm{~d}$. Sucrase activity increases with time after birth (Manners \& Stevens, 1972; Kidder \& Manners, 1980), so it would be predicted that the digestive capacity of sucrase would also continue to increase. However in the present experiment the capacity for sucrase hydrolysis decreased almost 2-fold after weaning.

The primary reason for the decrease in FruI after weaning was the large fructose adjusted AUC following treatment LAC + FRU (Table 2), which is the denominator in the calculation of FruI. This is an apparent $220 \%$ increase in the amount of fructose present in the peripheral circulation compared with that before weaning. It is difficult to imagine an increase in transport rate per se of this magnitude occurring in just $5 \mathrm{~d}$. For example, Puchal \& Buddington (1992) reported that at a physiological concentration of $5 \mathrm{~mm}$ (11 mM was given in the present study), fructose transport in the proximal small intestine increased from $11 \%$ of glucose transport at birth to $15 \%$ at $30 \mathrm{~d}$ of age. It is recognized that glucose and galactose are absorbed at a considerably faster rate than fructose, consistent with different mechanisms of transport across the epithelium (Williams, 1986). Glucose and galactose share one or more $\mathrm{Na}^{+}$-dependent carriers located in the brush-border membrane of apical villi that allows these two monosaccharides to be actively transported across the mucosa. They are also transported by facilitated and passive diffusion. In contrast, fructose moves into the lamina propria by means of a $\mathrm{Na}^{+}$-independent facilitated diffusion transporter having a low affinity for fructose (Puchal \& Buddington, 1992). Differences in the concentration of fructose in the lumen may cause differential changes in the rate of fructose absorption across the epithelium but, since the amount of fructose given was the same before and after weaning ( $2 \mathrm{~g})$ in the present experiment, it is unlikely that differences in transport rate are responsible for this disparity.

Another possibility is that the quantities of sucrose $(4 \mathrm{~g})$ and fructose $(2 \mathrm{~g})$ given in the present study may have exceeded the capacity of the enterocytes to digest sucrose and absorb fructose. If this was the case then the fructose adjusted AUC value after weaning may be a reflection of its longer half-life in the plasma and slower clearance after 
absorption. This might have been caused by an unexpected 'carry-over' of fructose from the first dose (e.g. treatment SUC+GAL) that was not completely cleared in the 90 min sampling period before the next dose (e.g. treatment LAC + FRU) was administered.

\section{Adjusted areas under the curves and villus height}

Our hypothesis that lactase activity, but not that of sucrase, would exhibit a positive relationship with villus height after weaning because maximal activity of lactase is present in enterocytes located more apically on the villus was only partly supported by the present study. Even though the adjusted AUC for both galactose and glucose following treatment LAC + FRU were highly correlated $\left(R^{2} 0.70\right.$ and 0.81 respectively) with villus height at the proximal jejunum, the adjusted AUC for glucose was also correlated with villus height at the same site following treatment SUC $+\mathrm{GAL}\left(R^{2} 0.74, P=0.027\right)$. This suggests that within the range of villus heights encountered in this study $(464-671 \mu \mathrm{m})$, lactase and sucrase showed increased activity in the upper part of the villus.

Correlations between villus height and the adjusted AUC for galactose and glucose following administration of both solutions were found at a site $25 \%$ along the small intestine only. The failure to detect relationships between lactose and sucrose digestion and villus height at sites 50 and $75 \%$ along the small intestine supports earlier research which suggests that lactase and sucrase activity in the young pig is maximal in the more proximal region of the small intestine (Manners \& Stevens, 1972; Kidder \& Manners, 1980; Shulman et al. 1988; Kelly et al. $1991 a-c$ ). These results also support the findings of Puchal \& Buddington (1992) who reported proximal to distal gradients in the rate and extent of galactose and glucose transport in sucking piglets. These findings illustrate the role of 'luminal nutrition' in determining gradients of disaccharidase activity along the small intestine of the young pig, a conclusion reached also by James et al. (1988) who examined lactase and sucrase activities in the weaned mouse.

\section{Adjusted areas under the curves and crypt depth}

Negative correlations were recorded between crypt depth at various sites along the gut and the adjusted AUC for glucose following both dosing treatments. An increase in crypt depth is indicative of an increased rate of enterocyte production and migration up the villi (Koldovsky et al. 1966; Al-Mukhtar et al. 1982). This results in proportionately more immature cells with reduced enzyme activity occupying the villus column because the rate of cell turnover is accelerated. The negative relationships observed in the present experiment are consistent with the proposition that pigs having a faster rate of enterocyte migration have a decreased capacity for lactose and sucrose hydrolysis. However, similar relationships were not observed for either galactose after lactose dosing (treatment LAC + FRU) or fructose after sucrose dosing (treatment SUC + GAL).

The decline in lactase and sucrase activities after weaning is generally associated with a decrease in villus height and in increase in crypt depth (Hampson \& Kidder, 1986). The faster rate of cell migration and reduction in villus height results in the remaining villus enterocytes having insufficient time to differentiate fully and express maximum catalytic capacity before being extruded from the villus tip (Rey et al. 1971; Tsuboi et al. 1981; Smith, 1984; Miller et al. 1986). In the present experiment we demonstrated that the AUC for galactose and glucose were positively correlated with villus height at the proximal jejunum because of the existence of maximal lactase (and sucrase) activity further away from the crypt:villus junction. Further analysis of the histological data revealed a significant negative relationship between villus height and crypt depth at a site $25 \%$ along 
the small intestine $\left(y=220 \cdot 7-0 \cdot 16 x, P=0 \cdot 018 ; R^{2} 0 \cdot 79\right)$, such that pigs having longer villi had a slower rate of cell turnover, or shorter crypts. This would result in a greater concentration of lactase and sucrase on the villus column because more mature enterocytes expressing maximum digestive capacity would be present. Although this association was only evident at the proximal jejunum, it accommodates both the negative relationship between crypt depth and the adjusted AUC for glucose, and the positive dependence between villus height and the amount of glucose present in the peripheral circulation following lactose and sucrose hydrolysis. However, why this should happen only with the adjusted AUC for glucose, and not for galactose or fructose, is unknown.

\section{Conclusions}

Villus height and crypt depth were maintained after weaning by the regular feeding of cows' whole milk. The capacity of the weaned pig to digest physiological boluses of lactose and sucrose and absorb their monosaccharide products increased between weaning and when pigs were killed $5 \mathrm{~d}$ later, as evidenced by an increased adjusted AUC for all monosaccharides. The GalI and FruI decreased after weaning despite increases in adjusted AUC for glucose, galactose and fructose following the digestion of lactose and sucrose. This incongruity may be explained by the increased growth (and hence surface area) of the small intestine such that total absorption per se may increase despite an apparent decrease in the enzymic activity in vivo of lactase and sucrase in the small intestine. Positive linear relationships between villus height and adjusted AUC for galactose and glucose following treatment $\mathrm{LAC}+\mathrm{FRU}$ and adjusted AUC for glucose following treatment SUC $+\mathrm{GAL}$ confirm maximum disaccharidase activity occurring more apically along the crypt:villus axis. Finally, we believe that this technique may be suitable for estimating the digestive and absorptive capacity of the small intestine in vivo in the weaned piglet, but suggest that the methodology requires validation using conventional starter diets rather than diets based on milk.

The authors wish to thank Rob Smits, the late Rosemary Head and Janine Toussaint for their technical assistance. Three of us (JRP, MJT and PHB) were in receipt of Postgraduate Research Fellowships from the Pig Research and Development Corporation of Australia.

\section{REFERENCES}

Al-Mukhtar, M. Y. T., Polak, J. M., Bloom, S. R. \& Wright, N. A. (1982). The search for appropriate measurements of proliferative and morphological status in studies on intestinal adaptation. In Mechanisms of Intestinal Adaptation, pp. 3--25 [J. W. L. Robinson, R. H. Dowling and E.-O. Riecken, editors]. Lancaster: MTP Press.

Altmann, G. G. (1972). Influence of starvation and refeeding on mucosal size and epithelial renewal in the rat small intestine. American Journal of Anatomy 133, 391-400.

Arthur, P. G., Kent, J. C. \& Hartmann, P. E. (1989). Microanalysis of the metabolic intermediate of lactose synthesis in human milk and plasma using bioluminescent methods. Analytical Biochemistry 176, $449-456$.

Bergmeyer, H. U. \& Bern't, E. (1974). D-Glucose: determination with glucose oxidase and peroxidase. In Methods of Enzymatic Analysis, 2nd ed., vol. 3, pp. 1205-1215 [H. U. Bergmeyer, editor]. New York: Academic Press.

Bird, P. H., Atwood, C. S. \& Hartmann, P. E (1995). The responses of blood galactose to oral doses of lactose, galactose plus glucose and milk to piglets. British Journal of Nutrition 73, 753-761.

Bird, P. H. \& Hartmann, P. E. (1994). The response in the blood of piglets to oral doses of galactose and glucose and intravenous administration of galactose. British Journal of Nutrition 71, 553-561.

Bird, P. H. \& Hartmann, P. E. (1996). Changes in the concentration of fructose in the blood of piglets of different ages after doses of fructose, fructose plus glucose and sucrose. British Journal of Nutrition 76, 399-407.

Brand Miller, J., Holt, S., Thomas, D., Byrnes, S., Denyer, G. \& Truswell, A. S. (1994). Glycaemic index: is it a useful tool in human health and disease? Proceedings of the Nutrition Society of Australia 18, 15-22.

Cera, K. R., Mahan, D. C., Cross, R. F., Reinhart, G. A. \& Whitmoyer, R. E. (1988). Effect of age, weaning and 
postweaning diet on small intestinal growth and jejunal morphology in young swine. Journal of Animal Science 66, $574-584$.

Clarke, R. M. (1975). The time-course of changes in mucosal architecture and epithelial cell production and cell shedding in the small intestine of the rat fed after fasting. Journal of Anatomy 120, 321-327.

Dahlquvist, A. \& Nordström, C. (1966). The distribution of disaccharidase activities in the villi and crypts of the small-intestinal mucosa. Biochimica et Biophysica Acta 113, 624-626.

Ekstrom, K. E., Benevenga, N. J. \& Grummer, H. (1975). Changes in the intestinal lactase activity in the small intestine of two breeds of swine from birth to 6 weeks of age. Journal of Nutrition 105, 1032-1038.

Gay, C. C., Barker, I. K. \& Moore, P. (1976). Changes in piglet intestinal villous structure and intestinal enzyme activity associated with weaning. In Proceedings of the IVth International Pig Veterinary Society Congress, vol. 5, p. 11 [W. E. Brandt, R. D. Glock, D. L. Harris, N. E. Hutton and A. D. Lennon, editors]. College of Veterinary Medicine, Iowa State University, Ames, Iowa: American Association of Swine Practitioners.

Goodlad, R. A., Plumb, J. A. \& Wright, N. A. (1988). Epithelial cell proliferation and intestinal absorptive function during starvation and refeeding in the rat. Clinical Science 74, 301-306.

Guppy, M., Sabaratnam, R., Devadason, S. \& Whisson, M. E. (1990). Fructose formation in store blood. Biochemistry International 21, 210-224.

Hampson, D. J. (1986a). Alterations in piglet small intestinal structure at weaning. Research in Veterinary Science 40, 32-40.

Hampson, D. J. (1986b). Attempts to modify changes in the piglet small intestine after weaning. Research in Veterinary Science 40, 313-317.

Hampson, D. J. \& Kidder, D. E. (1986). Influence of creep feeding and weaning on brush border enzyme activities in the piglet small intestine. Research in Veterinary Science 40, 24-31.

Hampson, D. J. \& Smith, W. C. (1986). Influence of creep feeding and dietary intake after weaning on malabsorption and occurrence of diarrhoea in the newly weaned pig. Research in Veterinary Science 41, 63-69.

Holmes, M. A., Arthur, P. G. \& Hartmann, P. E. (1990). Changes in the concentrations of glucose and galactose in the peripheral blood of suckling piglets. Journal of Dairy Research 57, 331-337.

Hornich, M., Salajka, E., Ulmann, L., Sarmanová, Z. \& Sedlácek, M. (1973). Enteric Escherichia coli infections. Morphological findings in the intestinal mucosa of healthy and diseased piglets. Veterinary Pathology 10, 484-500.

James, P. S., Smith, M. W. \& Tivey, D. R. (1988). Single-villus analysis of disaccharidase expression by different regions of the mouse intestine. Journal of Physiology $401,533-545$.

James, P. S., Smith, M. W., Tivey, D. R. \& Wilson, T. J. G. (1987). Epidermal growth factor selectively increases maltase and sucrase activities in neonatal piglet intestine. Journal of Physiology 393, 583-594.

Jonas, M. M., Montgomery, R. K. \& Grand, R. J. (1985). Intestinal lactase synthesis during postnatal development in the rat. Pediatric Research 19, 956-962.

Kaempf, J. W., Battaglia, F. C. \& Sparks, J. W. (1990). Galactose clearance and carbohydrate metabolism across the gastrointestinal tract in the newborn lamb. Metabolism 39, 698-703.

Kaempf, J. W., Li, H.-Q., Groothuis, J. R., Battaglia, F. C., Zerbe, G. O. \& Sparks, J. W. (1988). Galactose, glucose, and lactate concentrations in the portal venous and arterial circulations of newborn lambs after nursing. Pediatric Research 23, 598-602.

Kelly, D., King, T. P., McFadyen, M. \& Travis, A. J. (1991 a). Effect of lactation on the decline of brush border lactase activity in neonatal pigs. Gut 32, 386-392.

Kelly, D., Smyth, J. A. \& McCracken, K. J. (1990). Effect of creep feeding on structural and functional changes of the gut of early weaned pigs. Research in Veterinary Science 48, 350-356.

Kelly, D., Smyth, J. A. \& McCracken, K. J. (1991b). Digestive development in the early-weaned pig. I. Effect of continuous nutrient supply on the development of the digestive tract and on changes in digestive enzyme activity during the first week post-weaning. British Journal of Nutrition 65, 169-180.

Kelly, D., Smyth, J. A. \& McCracken, K. J. (1991c). Digestive development in the early-weaned pig. II. Effect of level of food intake on digestive enzyme activity during the immediate post-weaning period. British Journal of Nutrition 65, 181-188.

Kenworthy, R. (1976). Observations on the effects of weaning in the young pig. Clinical and histopathological studies of intestinal function and morphology. Research in Veterinary Science 21, 69-75.

Kidder, D. E. \& Manners, M. J. (1980). The level and distribution of carbohydrases in the small intestine mucosa of pigs from 3 weeks of age to maturity. British Journal of Nutrition 43, 141-153.

Kliegman, R. M. \& Sparks, J. W. (1985). Perinatal galactose metabolism. Journal of Pediatrics 107, 831-841.

Koldovsky, O., Sunshine, P. \& Kretchmer, N. (1966). Cellular migration of intestinal epithelia in suckling and weaned rats. Nature 212, 1389-1390.

Manners, M. J. \& Stevens, J. A. (1972). Changes from birth to maturity in the pattern of distribution of lactase and sucrase activity in the mucosa of the small intestine of pigs. British Journal of Nutrition 28, 113-127.

Miller, B. G., James, P. S., Smith, M. W. \& Bourne, F. J. (1986). Effect of weaning on the capacity of pig intestinal villi to digest and absorb nutrients. Journal of Agricultural Science, Cambridge 107, 579-589.

Miller, B. G., Newby, T. J., Stokes, C. R. \& Bourne, F. J. (1984). Influence of diet on postweaning malabsorption and diarrhoea in the pig. Research in Veterinary Science 36, 187-193. 
Nabuurs, M. J. A., Hoogendoorn, A., van der Molen, E. J. \& van Osta, A. L. M. (1993). Villus height and crypt depth in weaned and unweaned pigs, reared under various circumstances in the Netherlands. Research in Veterinary Science 55, 78-84.

Nabuurs, M. J. A., Hoogendoorn, A. \& van Zijderveld, F. G. (1994). Effects of weaning and enterotoxigenic Escherichia coli on net absorption in the small intestine of pigs. Research in Veterinary Science 56, 379-385.

Noblet, J. \& Etienne, M. (1987). Body composition, metabolic rate and utilization of milk nutrients in suckling piglets. Reproduction, Nutrition, Développement 27, 829-839.

Nordström, C. \& Dahlqvist, A. (1973). Quantitative distribution of some enzymes along the villi and crypts of human small intestine. Scandinavian Journal of Gastroenterology 8, 407-416.

Pluske, J. R., Williams, I. H. \& Aherne, F. X. (1996a). Maintenance of villous height and crypt depth in piglets by providing continuous nutrition after weaning. Animal Science 62, 131-144.

Pluske, J. R., Williams, I. H. \& Aherne, F. X. (1996b). Villous height and crypt depth in piglets in response to increases in the intake of cows' milk after weaning. Animal Science 62, 145-158.

Puchal, A. A. \& Buddington, R. K. (1992). Postnatal development of monosaccharide transport in pig intestine. American Journal of Physiology 262, G895-G902.

Rey, J., Schmitz, J., Rey, F. \& Jos, J. (1971). Cellular differentiation and enzymatic deficits. Lancet ii, 218.

Rice, L., Ott, E. A., Beede, D. K., Wilcox, C. J., Johnson, E. L., Lieb, S. \& Borum, P. (1992). Use of oral tolerance tests to investigate disaccharide digestion in neonatal foals. Journal of Animal Science 70, 1175-1181.

Shulman, R. J., Henning, S. J. \& Nicholls, B. L. (1988). The miniature pig as an animal model for the study of intestinal enzyme development. Pediatric Research 23, 311-315.

Siegel, C. D., Sparks, J. W. \& Battaglia, F. C. (1988). Patterns of serum glucose and galactose concentrations in term newborn infants after milk feeding. Biology of the Neonate 54, 301-306.

Smith, M. W. (1984). Effect of postnatal development and weaning upon the capacity of pig intestinal villi to transport alanine. Journal of Agricultural Science, Cambridge 102, 625-633.

Smith, M. W. \& James, P. S. (1987). Cellular origin of lactase decline in postweaned rats. Biochimica et Biophysica Acta 905, 503-506.

Spedale, S. B., Battaglia, F. C. \& Sparks, J. W. (1992). Hepatic metabolism of glucose, galactose, and lactate after milk feeding in newborn lambs. American Journal of Physiology 262, E46-E51.

Tsuboi, K. K., Kwong, L. K., D'Harlingue, A. E., Stevenson, D. K., Kerner, J. A. Jr \& Sunshine, P. (1985). The nature of maturational decline of intestinal lactase activity. Biochimica et Biophysica Acta 840, 69-78.

Tsuboi, K. K., Kwong, L. K., Neu, J. \& Sunshine, P. (1981). A proposed mechanism of normal intestinal lactase decline in the postweaned mammal. Biochemical and Biophysical Research Communications 101, 645-652.

Walker, D. M. (1959). The development of the digestive system of the young animal. Il. Carbohydrase enzyme development in the young pig. Journal of Agricultural Science 52, 357-363.

Williams, C. A. (1986). Metabolism of lactose and galactose in man. Progress in Biochemistry and Pharmacology 21, 219-247.

Williams, C. A., Philips, T. \& Macdonald, I. (1983). The influence of glucose on serum galactose levels in man. Metabolism 32, 250-256.

Wright, N. A. (1982). The experimental analysis of changes in proliferative and morphological status in studies on the intestine. Scandinavian Journal of Gastroenterology 17, Suppl. 74, 3-10.

Yeh, K. C. \& Kwan, K. C. (1978). A comparison of numerical integrating algorithms by trapezoidal, lagrange and spline approximation. Journal of Pharmacokinetics and Biopharmaceutics 6, 79-98. 